\title{
ERRATUM
}

\section{Erratum to: The Effect of Geography on HIV and Sexually Transmitted Infections in Tijuana's Red Light District}

Tommi L. Gaines, Melanie L. A. Rusch, Kimberly C. Brouwer, Remedios Lozada, Emily E. Perkins, Steffanie A. Strathdee, and Thomas L. Patterson

Erratum to: Journal of Urban Health Bulletin of the New York Academy of Medicine DOI 10.1007/s11524-012-9735-1

\section{ACKNOWLEDGMENTS}

This research was supported by NIDA grants R01DA02772-S1, R01DA028692, R00DA024135 and DA023877-S2.

The authors would like to acknowledge the work of Lucero Leon and Brieann O’Neill on creating maps for analysis.

Gaines, Rusch, Brouwer, and Strathdee are with the Division of Global Public Health, University of California, San Diego, USA; Lozada is with the Ministry of Health, State of Baja California, Tijuana, Mexico; Perkins is with the Department of Geography, San Diego State University, San Diego, CA, USA; Patterson is with the Department of Psychiatry, University of California, San Diego, La Jolla, CA, USA. Correspondence: Thomas L. Patterson, Department of Psychiatry, University of California, San Diego, La Jolla, CA, USA. (E-mail: tpatterson@ucsd.edu)

The online version of the original article can be found at doi: http://dx.doi.org/10.1007/s11524-012-9735-1. 